\title{
Isolation Screening and Selection of Phosphate Solubilizing Fungi from Soybean Rhizosphere
}

\author{
T.M. Premkumar*, V.P. Savalgi and G. Amrutha \\ Department of Agricultural Microbiology, College of Agriculture, Dharwad, \\ University of Agricultural Sciences, Dharwad, Karnataka, India \\ *Corresponding author
}

\section{A B S T R A C T}

Keywords

Phosphorus solubilization, Phytohormones, Biocompatibility

Article Info

Accepted:

26 February 2019

Available Online:

10 March 2019
Laboratory experiments were conducted to isolate screen and select the efficient Psolubilizing fungal isolates from soybean rhizosphere in the districts of Northern Karnataka. 24 P-solubilizing fungal isolates were obtained from the soil samples and were screened for phosphorus solubilizing ability on Pikovskaya's agar and broth BS-9(1) showed highest phosphorus solubilizing activity. Seven efficient isolates which were biocompatible with native soybean root nodulating bacteria (Bradyrhizobium Japonicum) were selected and assessed for other functional activities such as zinc and potassium solubilization, phytohormone production (IAA and $\mathrm{GA}_{3}$ ) and cellulolytic activity. All seven isolates were able to solubilize zinc and produce phytohormones. Among the seven isolates BS-6(1) was highest in phytohormone production and BS-6(1) and S-8(1) produced cellulase enzyme.

\section{Introduction}

Phosphorus is an important plant nutrient involved in several energy transformation and biochemical reactions including biological nitrogen fixation, root development, stalk and stem strength, flower and seed formation, crop maturity and production, crop quality and resistance to plant diseases are the attributes associated with phosphorus nutrition. Phosphorus is needed in relatively large amounts by legumes for growth and nitrogen fixation (Berg and Lynd, 1985). It is estimated that about 98 per cent of Indian soils are low to medium in available phosphorus, which is necessary to support maximum root growth. The uptake of phosphorus by the plant is only a small fraction of what is actually added as phosphate fertilizer. The unutilized phosphorus gets transformed to insoluble forms and fixed in the soil due to adsorption and precipitation. Phosphorus deficiency is widespread and phosphatic fertilizers are required to maintain crop production.

Soil microorganisms play an important role in making the phosphorus available to plants by mineralizing the organic phosphorus in the soil. These microorganisms have been isolated from a number of different soils in India. Several strains of phosphate- 
solubilizing microorganisms (PSMs) have been isolated from the rhizospheric soils of crops; of these 20 to 40 per cent are culturable soil microorganisms. A majority of the isolated organisms are bacterial organisms, although several fungi are also known to solubilize phosphates. These bacteria and fungi have the potential to be used as biofertilizers. Their role in increasing the soil nutrient value is of utmost importance. Their application to crop fields has resulted in an increased yield of several crops.

In soil, $\mathrm{P}$-solubilizing fungi constitute about 0.1-0.5 per cent of the total fungal populations (Kucey, 1983). Moreover, Psolubilizing fungi does not lose the $\mathrm{P}$ dissolving activity upon repeated sub culturing under laboratory conditions as the P-solubilizing bacteria do (Sperber, 1958; Kucey, 1983). Fungi in soils are able to traverse long distances more easily than bacteria and hence, may be more important to $\mathrm{P}$ solubilization in soils (Kucey 1983). Generally, the P-solubilizing fungi produce more acids than bacteria and consequently exhibit greater P-solubilizing activity (Venkateswarlu et al., 1984).The phosphorus solubilizing fungi are more efficient in phosphorus solubilization compared to the bacteria (Sanjotha et al., 2011).

Keeping in view with above information, an experiment is planned to Isolate, characterize and select phosphate solubilizing fungi from soybean rhizosphere.

\section{Materials and Methods}

The present investigation was carried out during the year 2016-17 in the Department of Agricultural Microbiology, University of Agricultural Sciences, Dharwad. Objectives of the present study were to isolate, screen and select the phosphorus solubilizing fungi from the soybean rhizosphere from different locations of northern Karnataka (Belagavi, Haveri, Dharwad districts). The soybean rhizosphere soil samples were collected from the three districts of Northern transition zone. Fungi were isolated from collected soil samples by serial dilution plate count method using Martin's Rose Bengal agar (MRBA) medium which is a selective medium for isolation of fungi. The isolated fungi were evaluated for their phosphate solubilising ability using Pikovskaya's medium, which is a selective medium for isolation of phosphate solubilizers. The amount of inorganic phosphorus $(\mathrm{Pi})$ released in the broth was estimated at 5, 10 and 15 days after incubation in comparison with the uninoculated control by phosphomolybdic blue colour method (Jackson, 1973).

The biocompatibility of PSF isolates was checked with native isolates used for soybean i.e. Bradyrhizobium japonicum (SB-120) and Pseudomonas striata by dual culture assay (Arfaoui et al., 2006; Negi et al., 2005). Based on the biocompatibility of the fungal isolates with Bradyrhizobium japonicum and Pseudomonas striata, seven phosphorus solubilizing fungal isolates were selected, recoded and used for further experiment. The morphological and functional characterization such as phytohormone production, zinc, potassium solubilization and cellulase activities were carried out for all the selected phosphorus solubilizing fungal isolates and the results obtained were as follows.

\section{Results and Discussion}

\section{Isolation and In vitro screening of phosphate solubilizing fungi (PSF)}

The rhizosphere soil samples of soybean were collected and used for the isolation of PSF. Out of 50 soil samples, 147 fungi were isolated, of which 24 isolates showed phosphate solubilizing ability. The isolated 
fungal colonies were observed for colony morphology. The isolates were assayed for in vitro phosphorus solubilization. The colour, type and shape of the phosphorus solubilizing fungal colonies were studied. The fungal isolates were grown on potato dextrose agar medium for one week at $28 \pm 2^{\circ} \mathrm{C}$ and the colony characters were recorded (Table 1).

Qualitative analysis of the isolates for phosphate solubilization is presented in Table 2. The diameter of zone of solubilization formed by the isolates ranged from 0.20 to $1.03 \mathrm{~cm}$ at 72 hours after incubation (HAI). Among the isolates BS-9-1 recorded maximum soluiblization zone.

The amount of inorganic phosphate (Pi) released in a broth by the isolates was studied at 5, 10 and 15 days after incubation (DAI). The results indicated that the amount of inorganic phosphate $(\mathrm{Pi})$ released by all isolates increased with increase in incubation time and it was maximum at 15 DAI. The $P i$ released by the isolates at 15 DAI ranged from $1.70 \mathrm{ppm}$ to $10.78 \mathrm{ppm}$. Among the isolates BS-4-3 released maximum amount of Pi (10.78 ppm).

Among the 24 PSF isolates, 8 isolates showed biocompatibility with the Bradyrhizobium japonicum (strain SB-120) and 7 isolates showed biocompatibility with both the Bradyrhizobium japonicum (strain SB-120) and Pseudomonas striata. All those 7 selected isolates of PSF were tentatively identified up to generic level based on their microscopic observation of spore structures and recoded. Four isolates were belongs to genera Aspergillus sp., two of them were belong to Penicillium sp. and one was unidentified (Table 3).

The 7 selected isolates were examined for the production of IAA and $\mathrm{GA}_{3}$. The amount of IAA and $\mathrm{GA}_{3}$ produced by the seven isolates was determined (at 13 and 10 DAI for IAA and $\mathrm{GA}_{3}$ respectively). The results are presented in Table 3. Among the isolates examined PSF-6 was found to produce the high amount of IAA $(7.29 \mu \mathrm{g} / \mathrm{ml}$ broth) and $\mathrm{GA}_{3}(3.25 \mu \mathrm{g} / 25 \mathrm{ml})$. None of the isolates showed the ability to solubilise potassium and all the selected PSF isolates showed zinc solubilizing ability. The selected seven PSF isolates were tested for their ability to hydrolyse cellulose on Carboxy methyl cellulose agar medium. Out of seven isolates only two isolates showed cellulolytic activity (Table 3).

The production of water-soluble phosphatic (WSP) fertilizers is a highly energy intensive process and about 75-90 per cent of the $P$ fertilizer applied to soil is precipitated by forming a complex with certain elements of the soil system and made unavailable to the plants system. $\mathrm{P}$ fertilizers are very expensive. Therefore, require the urgent attention needed across the globe so that an inexpensive alternative to chemical $\mathrm{P}$ fertilizers can be found.

Microorganisms play a key role in the field of agriculture by converting the unavailable form of nutrient to available form, thereby increasing its availability in soil and enhancing agricultural production In this regard, the microorganisms endowed with $\mathrm{P}$ solubilizing abilities have shown greater promise in agronomic practices under diverse agro-climatic zones of the world (Khan and Zaidi, 2007).

In the present study out of the 50 soil samples collected, 147 isolates of fungi were isolated and screened for their phosphate solubilizing ability. Among the isolates of fungi, 24 isolates showed their ability to solubilise phosphorus, it was confirmed by the production of halo zone around the colonies (Fig. 1). 
Table.1 Colony morphological characteristics of phosphate solubilizing fungal (PSF) isolates

\begin{tabular}{|c|c|c|c|c|}
\hline SI No. & Isolates & Colony colour & Texture & Margin \\
\hline 1 & S-1-1 & White with dark green center & Cottony growth & Round, even \\
\hline 2 & $S-1-2$ & White colony with brown center & Powdery flat & Uneven, round \\
\hline 3 & $\mathrm{~S}-2-3$ & White with creamish colony & Powdery flat & Round \\
\hline 4 & S-3-2 & Black & Flat & Round, even \\
\hline 5 & S-3-3 & White colony with brown center & Powdery flat & Uneven, round \\
\hline 6 & S-4-2 & White colony with brown center & Powdery flat & Uneven, round \\
\hline 7 & $S-5-2$ & Pinkish white & Cottony & Round, even \\
\hline 8 & $S-5-3$ & $\begin{array}{l}\text { White colony with yellowish } \\
\text { center }\end{array}$ & Flat powdery & Round, even \\
\hline 9 & S-6-1 & White & Flat & Round, even \\
\hline 10 & S-6-2 & Light green & Flat powdery & Round, even \\
\hline 11 & S-8-1 & Yellow & Cottony & Round, even \\
\hline 12 & S-10-1 & Olive green & $\begin{array}{l}\text { Flat with cottony } \\
\text { center }\end{array}$ & Round, even \\
\hline 13 & BS-1-1 & Black & Flat & Round, even \\
\hline 14 & BS-1-2 & Yellow & Flat & Round, uneven \\
\hline 15 & BS-2-3 & Black & Flat & Round, even \\
\hline 16 & BS-2-1 & Dark green & Cottony & Round, even \\
\hline 17 & BS-4-3 & Black & Flat & Round, even \\
\hline 18 & BS-6-1 & $\begin{array}{l}\text { Light green colony with dark } \\
\text { green center }\end{array}$ & Cottony & Round, even \\
\hline 19 & BS-6-3 & White & Cottony raised & Round, even \\
\hline 20 & BS-6-5 & Olive green with white margin & Powdery flat & Round, even \\
\hline 21 & BS-9-1 & Black & Flat & Round, even \\
\hline 22 & BS-19-1 & Black & Flat & Round, even \\
\hline 23 & DS-8-1 & Dark green & Cottony & Round \\
\hline 24 & DS-15-4 & Black & Flat & Round, even \\
\hline
\end{tabular}


Table.2 Zone of solubilization and Inorganic phosphate $(P i)$ release by the phosphorus solubilizing fungal isolates on Pikovskaya's agar and broth

\begin{tabular}{|c|c|c|c|c|c|c|}
\hline \multirow[t]{2}{*}{ Sl.No. } & \multirow[t]{2}{*}{ Isolates } & \multirow{2}{*}{$\begin{array}{c}\text { Zone of } \\
\text { solubilization } \\
\text { (cm) }\end{array}$} & \multirow{2}{*}{$\begin{array}{l}\text { Phosphate } \\
\text { solubilization } \\
\text { index }\end{array}$} & \multicolumn{3}{|c|}{$P i$ release (ppm) } \\
\hline & & & & $5^{\text {th }}$ day & $10^{\text {th }}$ day & $15^{\text {th }}$ day \\
\hline 1 & $S-5-2$ & 0.26 & 2.26 & 1.84 & 2.01 & 2.09 \\
\hline 2 & S-6-2 & 0.66 & 2.66 & 5.11 & 4.90 & 4.98 \\
\hline 3 & S-10-1 & 0.04 & 2.04 & 1.42 & 1.59 & 1.71 \\
\hline 4 & BS-2-1 & 0.69 & 2.69 & 2.84 & 3.89 & 4.02 \\
\hline 5 & S-3-2 & 0.95 & 2.95 & 8.71 & 9.44 & 9.75 \\
\hline 6 & BS-6-3 & 0.90 & 2.90 & 7.24 & 9.14 & 9.45 \\
\hline 7 & S-6-1 & 0.44 & 2.44 & 2.61 & 3.53 & 3.71 \\
\hline 8 & DS-8-1 & 0.95 & 2.95 & 5.99 & 7.30 & 7.54 \\
\hline 9 & BS-6-5 & 0.67 & 2.67 & 5.58 & 5.39 & 5.71 \\
\hline 10 & $S-1-2$ & 0.24 & 2.24 & 1.69 & 1.98 & 2.02 \\
\hline 11 & BS-1-1 & 0.98 & 2.98 & 6.56 & 8.25 & 8.58 \\
\hline 12 & S-1-1 & 0.48 & 2.48 & 1.41 & 4.44 & 4.55 \\
\hline 13 & BS-2-3 & 0.63 & 2.63 & 2.58 & 4.58 & 4.84 \\
\hline 14 & BS-1-2 & 0.80 & 2.80 & 1.39 & 1.54 & 1.70 \\
\hline 15 & $S-5-3$ & 0.35 & 2.35 & 1.43 & 3.13 & 3.29 \\
\hline 16 & BS-19-1 & 0.91 & 2.91 & 3.86 & 6.56 & 6.81 \\
\hline 17 & BS-6-1 & 0.92 & 2.92 & 5.11 & 5.96 & 6.18 \\
\hline 18 & $S-4-2$ & 0.39 & 2.39 & 2.56 & 3.28 & 3.54 \\
\hline 19 & BS-4-3 & 0.92 & 2.92 & 7.01 & 10.56 & 10.78 \\
\hline 20 & S-8-1 & 0.27 & 2.27 & 1.58 & 1.91 & 1.99 \\
\hline 21 & BS-9-1 & 1.03 & 3.03 & 8.17 & 9.86 & 10.14 \\
\hline 22 & S-3-3 & 0.20 & 2.20 & 1.50 & 1.72 & 1.86 \\
\hline 23 & S-2-3 & 1.02 & 3.02 & 2.66 & 5.83 & 6.16 \\
\hline 24 & DS-15-4 & 0.22 & 2.22 & 3.84 & 6.41 & 6.55 \\
\hline \multicolumn{2}{|c|}{ control } & - & - & 1.09 & 1.11 & 1.13 \\
\hline \multicolumn{2}{|c|}{ S. Em. \pm} & 0.092 & 0.092 & 0.028 & 0.027 & 0.028 \\
\hline \multicolumn{2}{|c|}{ C.D. @ 1\% } & 0.366 & 0.366 & 0.109 & 0.107 & 0.111 \\
\hline
\end{tabular}


Table.3 Tentative identification of selected biocompatible PSF isolates based on microscopic observations and their functional characterization

\begin{tabular}{|c|c|c|c|c|c|c|c|c|}
\hline Sl. No & Isolates & $\begin{array}{l}\text { Recoded } \\
\text { isolates }\end{array}$ & $\begin{array}{c}\text { Probable } \\
\text { genus }\end{array}$ & $\begin{array}{c}\text { K } \\
\text { solubilization }\end{array}$ & $\begin{array}{c}\mathrm{Zn} \\
\text { Solubilization }\end{array}$ & $\begin{array}{c}\text { IAA } \\
(\mu \mathrm{g} / \mathrm{ml})\end{array}$ & $\begin{array}{c}\mathbf{G A}_{3} \\
(\boldsymbol{\mu g} / 25 \mathrm{ml})\end{array}$ & $\begin{array}{c}\text { Cellulolytic } \\
\text { activity }\end{array}$ \\
\hline 1 & S-8-1 & PSF-1 & Penicillium sp & - & + & 6.83 & 2.98 & + \\
\hline 2 & S-1-2 & PSF-2 & Aspergillus sp & - & + & 5.51 & 2.76 & - \\
\hline 3 & $S-3-3$ & PSF-3 & Aspergillus $s p$ & - & + & 6.32 & 2.15 & - \\
\hline 4 & S-5-2 & PSF-4 & Unidentified & - & + & 6.28 & 2.53 & - \\
\hline 5 & S-6-1 & PSF-5 & Aspergillus $s p$ & - & + & 6.47 & 2.61 & - \\
\hline 6 & BS-6-1 & PSF-6 & Penicillium $s p$ & - & + & 7.29 & 3.25 & + \\
\hline 7 & S-4-2 & PSF-7 & Aspergillus sp & - & - & 5.36 & 2.47 & - \\
\hline Note & $\begin{array}{l}\text { IAA- In } \\
\text { GA- Gil }\end{array}$ & $\begin{array}{l}\text { acetic ac } \\
\text { c acid }\end{array}$ & & $\begin{array}{l}\text { tassium } \\
\text { ositive }\end{array}$ & $\mathrm{Z}$ & & & \\
\hline
\end{tabular}


Fig.1 Inorganic phosphate $(\mathrm{Pi})$ release by the phosphorus solubilizing fungal isolates in Pikovskaya's broth

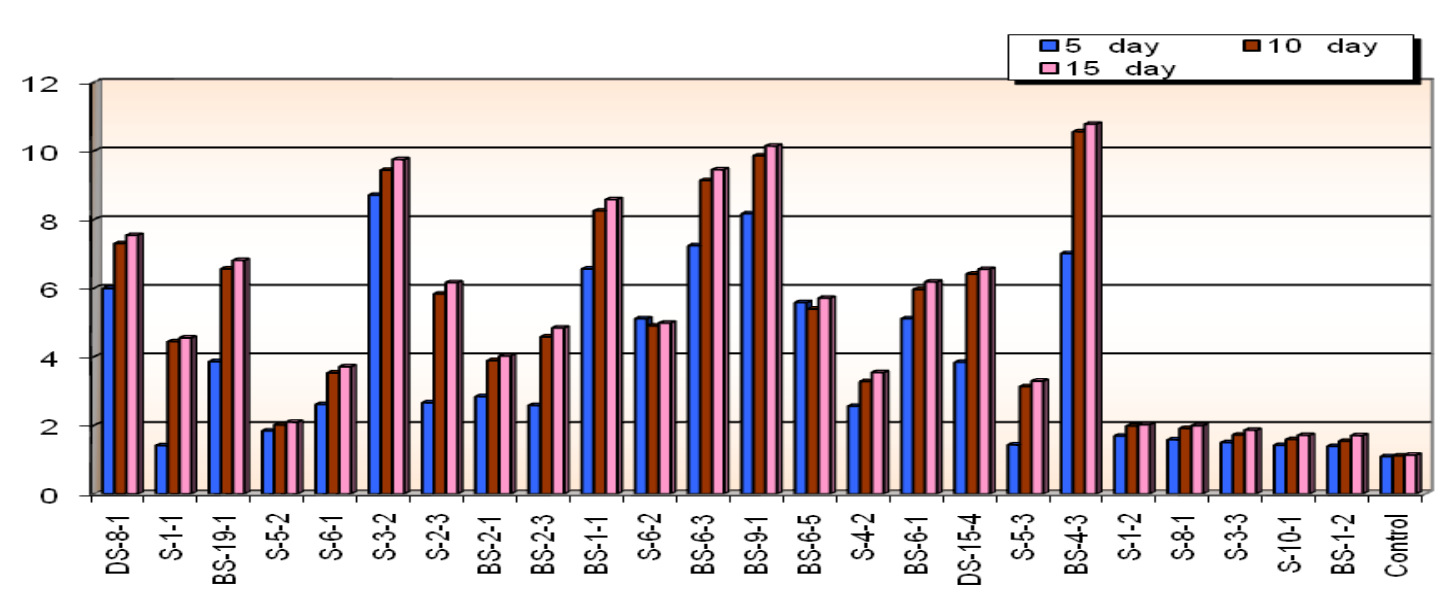

Plate.1 Phosphate solubilization by the fungal isolates on Pikovskaya's agar

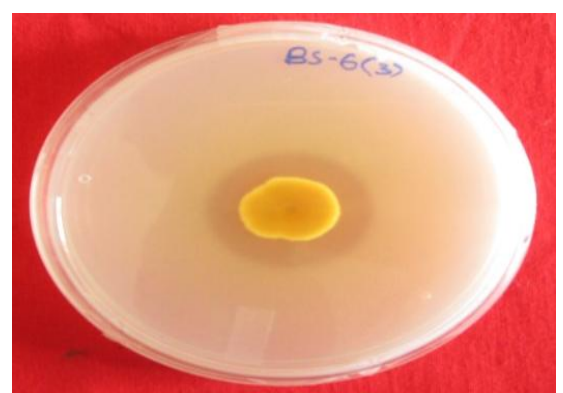

a) BS-6-3

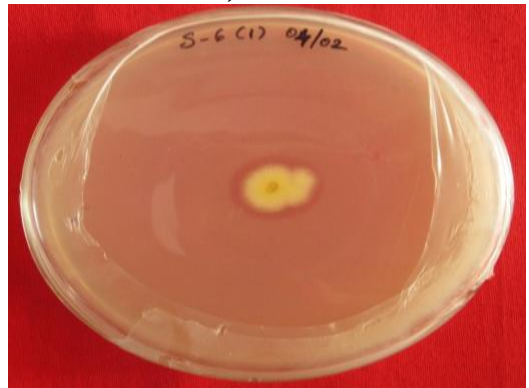

c) $\mathbf{S - 6 - 1}$

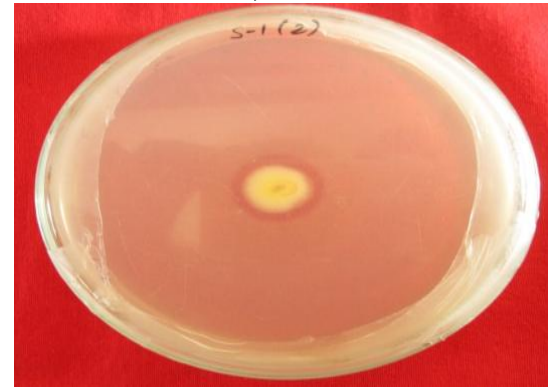

e) $\mathrm{S-1-2}$

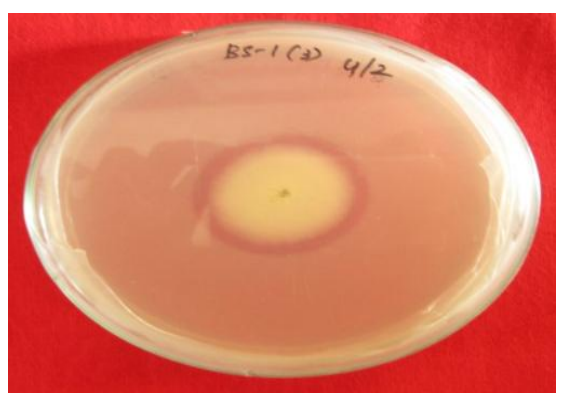

b) BS-1-3

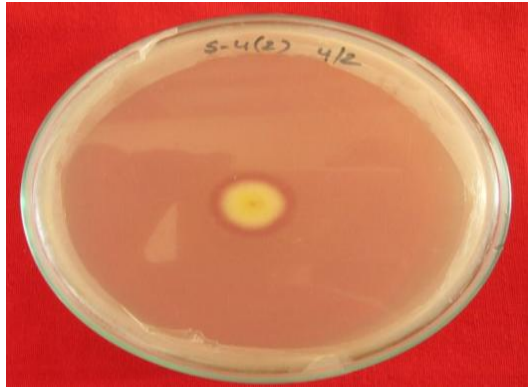

d) $\mathbf{S - 4 - 2}$

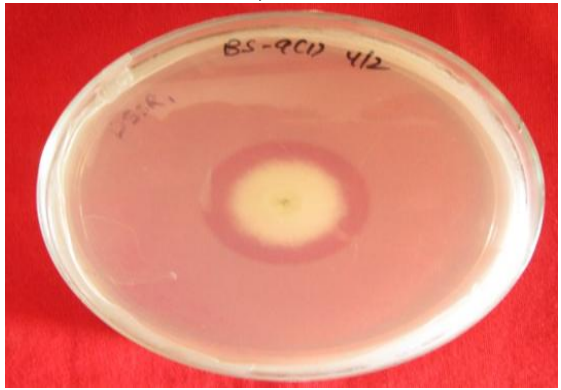

f) BS-9-1 
Plate.2 Colony morphology and microscopic view of different PSF isolates

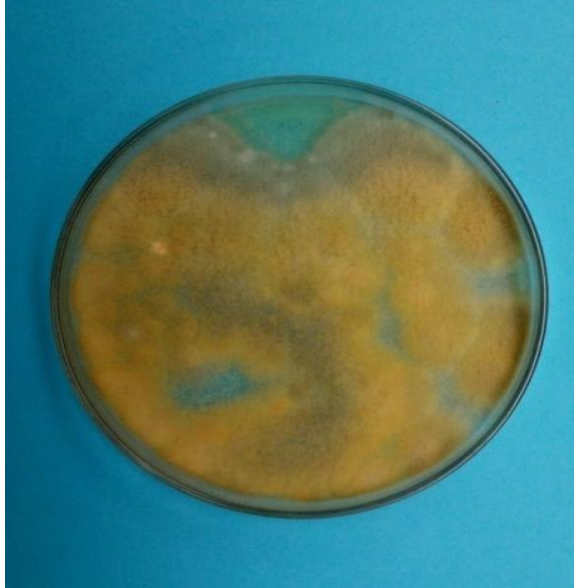

a) $\mathbf{S - 8 - 1}$

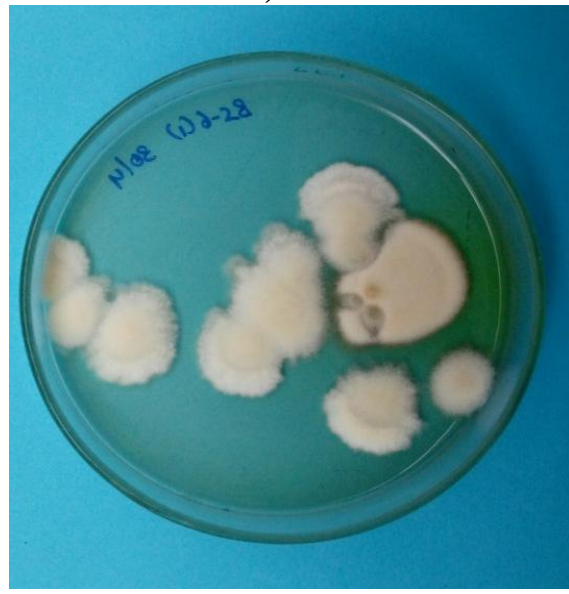

c) $\mathrm{BS}-6-1$

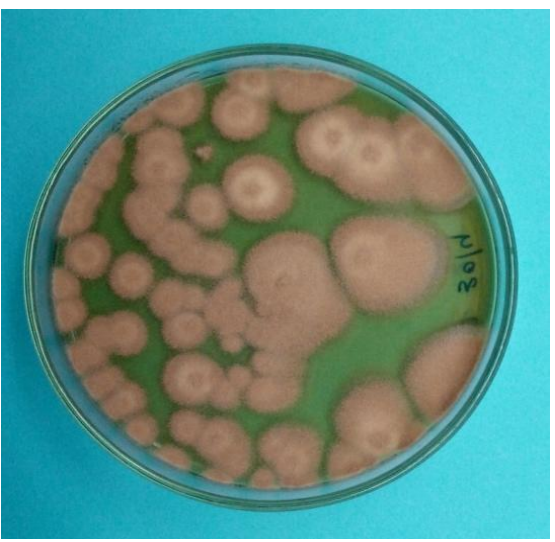

e) $\mathbf{S - 3 - 3}$

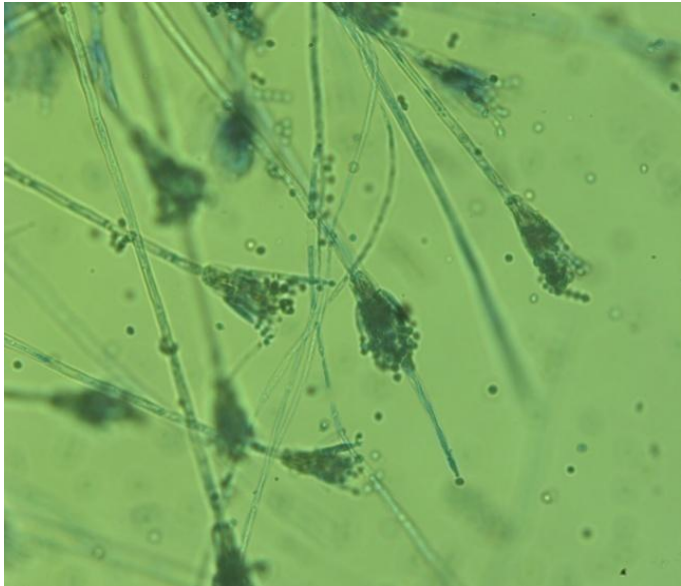

b) Penicillium sp.

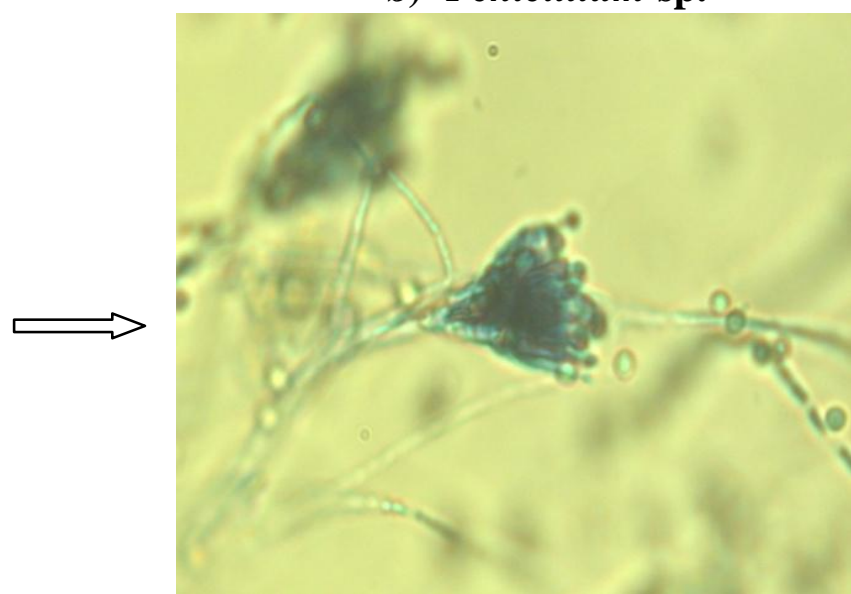

d) Penicillium sp.
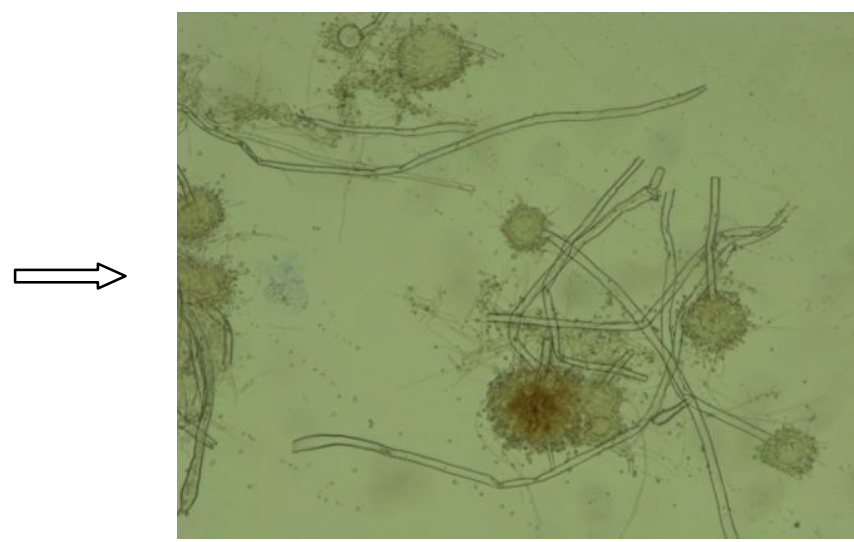

f) Aspergillus sp. 
The typical colony characters of the isolated PSF that appeared on Pikovskaya's agar ranged from flat powdery to raised and the colour of the colonies were green, black, brown, orange and white. The margin of the colony was either even or uneven. The isolated PSF were purified and maintained.

The fungal isolates found to solubilize phosphorous to varying degrees. However, they were found to differ both in efficiency as observed from the formation of clear halos around their colonies and solubilization index based on colony diameter and halo zone. The phosphate solubilization by the isolated fungi increased with incubation time upto 15 days. The results also indicated variability in the amount of phosphate released by different isolates. The differential efficiency of PSF isolates for phosphate solubilization may have been due to the nature and quality of organic acids secreted in the medium as suggested by Iman and Azouni (2008), Malviya et al. (2011), Tam et al. (2016).

The inhibitory effect of P-solubilizing fungi on the associative partners could be due to the release of toxins in the growing environment which might affect the functional symbioses between rhizobia and their specific legume host plants. These results therefore, suggest that, before carrying out in situ experiments, the compatibility between the two associate members must be checked in vitro (Aziz et al., 1998). With this background, PSF isolates were checked for biocompatibility with Bradyrhizobium japonicum and Pseudomonas striata. Seven isolates were biocompatible. Based on microscopic analysis using lactophenol cotton blue, the fungal isolates were tentatively identified as Aspergillus sp and Penicillium sp. Apart from solubilization of insoluble phosphates, the phosphate solubilizers are known to possess other beneficial properties like production of plant growth promoting substances, Zinc mineral solubilizaion and cellulolytic activity.
Phosphate solubilizing fungi were also examined for production of IAA and $\mathrm{GA}_{3}$. All the seven selected PSF isolates were considered as positive for phytohormone production. Six PSF isolates were considered as positive for zinc mineral solubilisation. Zinc solubilization by the fungal isolates could be due to the production of organic acids, in which acidification was expected to solubilise zinc (Maheshwar and Sathiyavani, 2012). Cellulose hydrolysis is an important trait in ecological fitness of an organism for better survival in the rhizosphere (Boer et al., 2005). Two PSF isolates were positive for hydrolysis of cellulose which was confirmed by the formation of halo zone against red colour around the fungal colonies grown on carboxy methyl cellulose agar medium.

Thus, the findings of the present investigation have brought out the role and efficiency of fungi in solubilizing insoluble phosphate, zinc, and hydrolysis of cellulose, production of phytohormones (IAA and $\mathrm{GA}_{3}$ ) which may help in growth of the plant when they are used as biofertlizers.

\section{References}

Arfaoui, A., Sifi, B., Boudabous, A., Hadrami, I. E. and Cherif, M., 2006, Identification of Rhizobium isolates possessing antagonistic activity against Fusarium oxysporum f. sp. Ciceris, the causal agent of Fusarium wilt of chickpea. J. Plant Pathol., 88(1): 67-75.

Aziz, N. H., Yousef, Y. A., Moheie, Z. E. and Moussa, L. A., 1998, Contamination of some common medicinal plant samples and spices by fungi and their mycotoxins. Botan. Bull. Academia Sinica, 39: 279285.

Berg, R. K. and Lynd, J. Q. (1985). Soil fertility effects on growth, yield, nodulation and nitrogenase activity of Australian winter pea. J. Plant Nutr., 8:131-145.

Boer, W. D., Folman, L. B., Richard, C. S., and 
Lynne, B., 2005, Living in a fungal world: impact of fungi on soil bacterial niche development. FEMS Microbiol. Rev. 29(4):795-811.

Iman, M. and Azouni, E., 2008, Effect of phosphate solubilizing fungi on growth and nutrient uptake of Soybean (Glycine max L.) plants. J. Appl. Sci. Res., 4(6): 592-598.

Jackson, M. L., 1973, Soil Chemical Analysis, Prentice Hall of India Private Limited, New Delhi, 38-82.

Khan, M. S. and Zaidi, A., 2007, Synergistic effects of the inoculation with plant growth promoting rhizobacteria and arbuscular mycorrhizal fungus on the performance of wheat. Turkish J. Agril. Forest, 31: 355-362.

Kucey, R. M. N., 1983, Phosphate solubilizing bacteria and fungi in various cultivated and virgin Alberta soils. Canadian J. Soil Sci., 63: 671-678.

Maheshwar, N. U. and Sathiyavani, G., 2012, Solubilization of phosphate by Bacillus spp. from groundnut rhizosphere (Arachis hypogaea L.). J. Chem. Pharm. Res., 4: 47.

Malviya, J., Singh, K. and Vaibhavi, J., 2011, Effect of phosphate solubilizing fungi on growth and nutrient uptake of ground nut (Arachis hypogaea) plants. Adv. Biores. 2(2): $110-113$.

Negi, Y. K., Garg, S. K. and Kumar, J., 2005, Cold tolerant fluorescent Pseudomonas isolates from Garhwal Himalayas as potential plant growth promoting and biocontrol agents in pea. Curr. Sci., 89:2151-2156.

Sanjotha, P., Mahantesh, P. and Patil, C.S., 2011, Isolation and screening of efficiency of phosphate solubilizing microbes. Int. J. Microbial. Res., 3(1): 56-58.

Sperber, J. I., 1958, The incidence of apatitesolubilizing organisms in the rhizosphere and soil. Australian J. Agril. Res., 9: 778781.

Tam, H. T., Minh, T. M. C.and Cao, N. D., 2016, Isolation and identification phosphate-solubilizing fungi from ferralsols of tithonia (Tithonia diversifolia (Hamsl.) Gray) in Daknong and Daklak province(s), Vietnam. World J. Pharmacy Pharmaceutical Sci., 5(9): 325-342.

Venkateswarlu, B., Rao, A.V., Raina, P. and Ahmad, N., 1984, Evaluation of phosphorus solubilization by microorganisms isolated from arid soil. $J$. Indian Soc. Soil Sci., 32: 273-277.

\section{How to cite this article:}

Premkumar, T.M., V.P. Savalgi and Amrutha, G. 2019. Isolation Screening and Selection of Phosphate Solubilizing Fungi from Soybean Rhizosphere. Int.J.Curr.Microbiol.App.Sci. 8(03): 2572-2581. doi: https://doi.org/10.20546/ijcmas.2019.803.305 